\title{
Por qué sigue llorando Efraín o cómo leemos María en el siglo XXI
}

\section{Natalia Crespo}

Natalia Crespo es profesora asistente de español y estudios latinoamericanos en la Universidad Tecnológica de Michigan. Contacto:

Universitynmcrespo@mtu.edu El presente ensayo es una versión abreviada del capítulo que lleva el mismo título y que será publicado en el libro Parodias al canon nacional en Ia literaturalatinoamericana contemporánea (1975-2000), en noviembre de 2011 por la Editorial Corregidor. 
PALABRAS CLAVE

María, Efraín, nostalgia, tensión, recepción

KEYWORDS

María, Efraín, nostalgia, tension, reception

\section{Resumen}

A la luz de cómo se lee María en el siglo XXI y de cómo se la ha leído en el XIX, en este ensayo se profundiza en algunos aspectos textuales que, hasta el momento, no han sido del todo resueltos por la crítica: la problemática de la doble enunciación expresada en la dedicatoria, la tensión entre la obediencia de Efraín y su sometimiento, la relación entre la dimensión trágica del texto, el prestigio socio-cultural del sufrimiento y el proceso de canonización en el siglo XIX. Se intenta indagar en torno a los aspectos considerados "moralizantes" y a aquellos que la crítica tilda de "vergonzantes".

\section{Abstract}

Taking into consideration processes of reception of María (from Nineteenth-Century to current articles) this essay explores some textual aspects of this canonical novel not completely clarified yet by the precedent bibliography: the duality of the enunciation of the dedicatory, the tension between Efraín's submissive discourse in his oral interventions and his mild opposition in his role as narrator, the socio-cultural prestige of tragedy, the process of canonization of the novel during its reception in Nineteenth-Century, as opposed to the condemning reading of our century. 
A CASI UN SIGLO Y MEDIO DE SU PUBLICACIÓN y con un corpus importante de lecturas críticas, María (I867), la novela romántica decimonónica más leída en Latinoamérica ${ }^{\mathrm{I}}$, nos sigue cautivando. Como Efraín - el protagonista y narrador que, por mucho que se esmera, no logra llegar antes de la muerte de la amada -, la crítica nunca llegará al completo des-cubrimiento de la novela o, en palabras de Noé Jitrik, "la crítica no ha logrado acabar con su extraño atractivo" (2006, I3). Pero los lectores contamos con una gran ventaja respecto del atribulado joven ante el esquivo objeto de deseo: no hace falta que lloremos.

Monserrat Ordóñez se preguntó - a propósito de la Historia de la Literatura de la Nueva Granada (1867) de José María Vergara y Vergara - quién, hoy en día en Colombia, quiere verdaderamente re-leer la literatura del siglo XIX. Según esta crítica, dicha falta de interés en la literatura fundacional se debe a cierto impulso por "borrar versiones de nosotros mismos en las que no queremos reconocernos porque en estos momentos reconocernos en ellas implicaría aceptar varios aspectos ambiguos de nuestra historia y de nuestra literatura" (I988, II). ¿Por qué María es - o no es - interesante para los lectores del siglo XXI? ¿A qué “versiones de nosotros mismos" se refiere Ordóñez? Tanto la novela de Isaacs como la historia literaria de Vergara, desde nuestros parámetros éticos del siglo XXI - más pacatos que practicados - están lejos de ser obras con ideologías políticamente correctas: en ambas se presupone una sociedad de jerarquías rígidas, de amos y esclavos, hombres blancos patriarcales y mujeres domésticamente sumisas, sin indígenas y con algunos negros que, además de ser pocos, son alegremente dóciles².

I Así lo explica Susana Zanetti en "María de J. Isaacs y los problemas de constitución de un canon de América Latina. Aspectos internacionales de independencia literaria" (2001).

2 Sobre la exclusión de los indígenas en la Historia de la literatura de la Nueva Granada (1867), de Vergara, en tanto correlato de la exclusión de este grupo étnico en la sociedad, escribe Patricia D'Allemand: "The exclusion of the indigenous written production from the corpus of Latin American national literatures obviously stems from the creoles' perception of indigenous civilizations as a thing of the past, since the 
Ahora bien, estos aspectos ideológicamente condenables (los que, según Ordóñez, nos avergüenzan hoy): ¿son monolíticos o presentan fisuras? En tensión con lo que hoy consideramos vergonzoso, en el siglo XIX la novela constituía un caso de ejemplaridad moral. ¿En virtud de qué aspectos textuales - o de recepción - la novela se convirtió en canon escolar, en pieza moralizante y marmolada? Éstas son algunas de las preguntas que guían el presente ensayo, en el que me propongo ahondar en algunos problemas no del todo resueltos hasta ahora por la crítica: el conflicto enunciativo de la dedicatoria; la tensión entre el discurso de Efraín narrador y el discurso de Efraín personaje (en sus intervenciones orales es claramente sumiso, sin atisbos de rebeldía), el prestigio socio-cultural del dolor y las primeras lecturas canonizantes de María.

\section{LA DEDICATORIA O LA CON-FUSIÓN DE VOCES}

En la ya célebre dedicatoria se nos anticipa: “Lo que ahí falta tú lo sabes: podrás leer hasta lo que mis lágrimas han borrado.” Según la novela, la frase fue dicha por el propio Efraín al amigo a quien le ha encomendado sus manuscritos. Este amigo se encarga de transformar "el libro de sus recuerdos" [los de Efraín, ahora fallecido] en la novela que les llega "a los hermanos de Efraín” y a los lectores, es decir, que este amigo sería algo así como un editor. En palabras de Díaz Balsera, "el texto se representa como habiendo sido editado por un

process of conquest and colonization was thought to have sealed their destruction (219)". Por otro lado, respecto del tratamiento de la esclavitud y de los negros en María Carol A. Beane ha esbozado la idea del "placer de colonizar", médula ósea del conservadurismo en María: "[...] el episodio de Nay y Sinar en María postula la barbarie como signo de inferioridad del africano, del negro. Dicha barbarie e inferioridad reclaman una autoridad superior para administrarlas. [...] La representación de África a través de las referencias de Cantú en la obra de Isaacs es reveladora, ya que por su tono y modo éstas se asocian con obras más explícitamente colonialistas que aparecerán luego. Nos ayuda a ver con mayor claridad el placer de colonizar en la reconstrucción nostálgica de la vida en El Paraíso que hace Efraín" (Beane, 208). 
POR QUÉ SIGUE LLORANDO EFRAÍN O CÓMO LEEMOS MARÍA EN EL SIGLO XXI

NATALIA CRESPO

amigo del narrador a partir de las memorias que Efraín le había dejado” (ı998, 38). Silvia Molloy también comenta brevemente el paradigma de la dedicatoria: “Lo borrado es lo que precisamente hizo surgir las lágrimas y el escriba - experto en pathos - tendrá que restituirlo, y acaso magnificarlo, para provocar las lágrimas del lector" (I984, 37). El recurso literario del manuscrito ajeno encomendado a una segunda persona deja en la nebulosa la diferenciación entre la escritura de Efraín y la del amigo. Invitados a este juego de voces, los lectores no sabemos quién es exactamente este amigo que escribe la dedicatoria pero, sobre todo, desconocemos qué transformaciones hizo sobre los papeles que le dejara Efraín - si es que transformó algo -. Comenta este amigo difuso, casi en tono dialógico al respecto de lo leído en la frase supuestamente enunciada por Efraín: "Después de escritas me han parecido pálidas e indignas de ser ofrecidas como un testimonio de mi gratitud y de mi afecto". Si el amigo ha sido sólo editor y no escritor colaborador, ¿por qué hace este comentario? La frase, más que de un editor, parece un gesto de falsa modestia de alguien que ha tomado parte activa en la redacción. Entonces: ¿quién escribió verdaderamente la novela: ¿Efraín, el amigo anónimo o ambos? ¿Qué ha escrito cada uno? ¿Cómo era el texto de Efraín y qué agregó o quitó el amigo? ¿Qué es lo que "las lágrimas han borrado"? ¿Cuán sustancial es la distancia entre los papeles que entregara Efraín y el resultado que les llega a los hermanos (es decir, la novela que nos llega a los lectores)? Esta indeterminación enunciativa nos va adentrando en la estética romántica que predomina en María: al tiempo que enfatiza el espesor dramático de la muerte del protagonista, nos sugiere una suerte de fusión de voces (y de prosas) entre los dos amigos. La comunión entre ambos jóvenes es tal -parece sugerir esta dedicatoria - que el amigo anónimo es capaz de adivinar qué falta en cada lugar y suplir esos vacíos con sus recuerdos.

Si optamos por una interpretación literal de la "Dedicatoria”, el poder supletorio de la prosa del amigo se rectificará en el momento en que los hermanos 
de Efraín viertan, al leer el texto, lágrimas tan dolorosas como aquellas de Efraín que han borrado fragmentos del manuscrito: “iDulce y triste misión!”, se queja el escribiente anónimo, "Leedlas, pues, y si suspendéis la lectura para llorar, ese llanto me probará que la he cumplido fielmente”3. Aunque las lágrimas de Efraín atentaron contra la completitud del texto - han borrado partes - también es cierto que serán prueba de éxito literario, según la estética sentimentalista.

\section{EFRAÍN NARRADOR VS. EFRAÍN DIALÓGICO}

Quizás no sea desacertado pensar a María como la narración de dos historias simultáneas. La más evidente sería la historia de la lucha entre el amor y la muerte como fuerzas contrarias que unen o separan a los amantes. La

3 Sobre el tema de las lágrimas en María - ya sean las que el autor busca suscitar en el lector o las que derraman los personajes - se han ocupado, al menos, Luis Carlos Velasco Madriñán, Eduardo López Morales, Silvia Molloy y Juan Cantavella. El primero, famoso biógrafo del autor, tituló su libro Jorge Isaacs, el caballero de las lágrimas. López Morales, por su parte, comenta que por "los abundantes torrentes que arrancó a una adolescencia preferentemente femenina" y por "la frecuencia de lágrimas, sollozos y demás variedades de pluviosidad ocular que afloran en la novela", el problema de la novela no reside en haber iniciado el Romanticismo en América Latina sino en "haberlo culminado en su vertiente sentimental, que parte de los modelos de Lamartine y Chateaubriand y que tiene, justamente a Jorge Isaacs y a Zorrilla de San Martín en la poesía como (Tabaré), como sus dignos términos de camino" (Citado por Cantavella, 1996, 96). Cantavella ha afirmado no sin exageración: "La felicidad y el dolor, el encuentro y la separación, todo se resuelve en lágrimas. No hay ninguna novela romántica, ni entre las americanas de la época, ni entre las francesas que le sirven de modelo, que produzcan mayor cantidad de penas y suspiros. Desde el principio hasta el fin, apenas hay una página que no se halle bañada por el llanto" (96). Mejía Duque cita las propias palabras de Isaacs en referencia a su novela: “¡Páginas queridas, demasiado queridas quizás! Mis ojos han vuelto a llorar sobre ellas. Las altas horas de la noche me han sorprendido varias veces con la frente apoyada sobre estas últimas, desalentado, para trazar algunos renglones más" (citado por Cantave1la, 97). Explica Molloy: "El 1lanto, sólo aparentemente espontáneo, ha sido sabiamente calculado: remite a un criterio de lectura de una época y es índice de recepción. Así, con lágrimas, se leen las fícciones de amor insatisfecho [...]. El llanto en María no sólo aparece abundantemente tematizado sino que es criterio de excelencia para el lector experto $(1984,37)$ ". 
segunda, implícita pero tan importante como la primera, sería la historia de la lucha entre la obediencia y la desobediencia, entre el deber - representado por la figura del padre - y el deseo - el amor entre Efraín y María -; o bien entre los intereses de una sociedad - manifestada en su mínima expresión, la familia - y el individuo, Efraín.

Algo de esto ya ha sido planteado. Son varios los críticos que analizaron la dualidad en María, ya sea de estilos literarios (romántico vs. realista) o la dualidad de estratos sociales (amos vs. esclavos), o la dualidad entre la felicidad de los sometidos vs. la infelicidad de los dueños de la tierra, o bien la dualidad de géneros, cuyos roles están bien tabicados y jerarquizados 4 .

Hay una tensión, un doblez del discurso, entre lo que se dice en voz alta (Efraín dialógico, siempre de acuerdo no por sometimiento sino por natural

4 Rodolfo Borello, poniendo el énfasis en la estructura jerárquica de la hacienda y teniendo en mente - creemos - la dicotomía sarmientina de civilización y barbarie, propone: "El mundo social que la novela describe está claramente dividido en dos grupos muy diferenciados: los amos y los esclavos o, para decirlo con menos rudeza: una clase terrateniente y otra de esclavos manumitidos y arrendatarios (I997, 68)”. Y, más adelante, agrega: “Unos, los de abajo, pertenecen a la esfera de la naturaleza [...] Frente a ellos, y en otro plano, están los habitantes de la casa, los poseedores” (I997, 70). Para Díaz Balsera (y también, antes, para Magnarelli y para Lagos-Pope) la novela muestra claramente los roles masculinos y femeninos tabicados en espacios públicos y privados respectivamente y, por supuesto, jerarquizados: "En este momento, el triunfo de la burguesía que es el siglo XIX en que se escribe María, la subjetividad de las mujeres que pertenecen a la clase dominante se la construye como algo seráfico. La mujer del patriarca es un ángel doméstico cuya función es la de velar por el núcleo, unidad clave de la nueva sociedad" (I998, 42). Sin embargo, la novela "representa la mejor cara del patriarcado, el espacio más armonioso y deseable que éste pueda producir (40)”. Y, no obstante, a pesar de ser lo más idealizable del patriarcado, la sociedad representada no deja de tener fisuras: "Esta casa es un espacio jerárquico, ritual, ordenado, en que impera sin resistencia, sin fricciones u oposición, la voluntad todo prestigiosa del padre. [...] Y, sin embargo, la falta de resistencia, la ausencia de confrontación, la tranquilidad y armonía no implican la erradicación de los signos de la violencia en este espacio paradisíaco" (40). 
empatía con el padre) y lo que se narra (allí sí, a través de la voz más escrituraria y menos oral, hay un cierto rechazo del mundo paterno). Ahora bien, este rechazo no es, claro, abierto, pero sí rastreable. Se da a través de todo aquello que construye la figura del padre con una faz sádica. En un plano narratológico, a través del desvío de la narración hacia lugares periféricos, circundantes a la casa paterna, pero donde habitan seres de otra clase social que son felices: (¿de qué me sirve mi linaje, mis capitales real y simbólico - cultura, poesía - parecería decirnos Efraín, si ellos, con tanto menos, son felices?).

En este desvío de la focalización del relato haya quizás una intención relentificadora, de demorar el desenlace para generar suspenso, o quizás se trate tan sólo de una intención descriptiva exhaustiva del escritor naturalista que quiere dar cuenta de la "colombianidad" de su tierra. Pero también, creemos, hay un rechazo del Efraín narrador hacia la esfera paterna.

Porque conocemos el final fracasado de ambas luchas desde el inicio del texto, el valor de María reside menos en el desenlace argumental (que tiene, sin embargo, sus momentos de suspenso) que en el relato, a veces alegórico, a veces explícito, de todo lo que podría haber sido y no fue. Se narra - desde esta enunciación doble: apuntes de Efraín mediados por su editor - una vez que los personajes más importantes han muerto: el padre, María, Efraín. Si bien esto es triste, y lo sabíamos desde el comienzo - tenemos conocimiento de que el amor que se nos va a contar ha sido imposible -, el sentido trágico radica en cómo se despliega narrativamente esa imposibilidad. ¡Cuán felices podrían haber sido los amantes de no haber muerto! Este condicional - podrían, pero no fueron - es clave para la fatalidad del relato: la novela cuenta recurrentemente todo lo que podría haber sido y no fue. La tragicidad no reside sólo en las muertes per se (dato que tenemos desde el comienzo, en una especie de crónica de muertes anunciadas) sino en la idealización imaginaria de lo que no ocurrió: la nostalgia de lo irrealizado. 
Así, quizás muchos de los elementos colindantes a la historia de María y Efraín - las bodas de Braulio y Tránsito, los amores de Tiburcio y Salomé, las descripciones costumbristas de José y de su familia, la historia de Nay y Sinar, hasta incluso la presencia del pequeño Juan - entre otras cosas, enfatizan el sentido trágico de la historia central, nos recuerdan la dimensión de la pérdida.

El pequeño Juan, por ejemplo, tiene con María una relación de hijo, como si su madre fuera en verdad la prima adoptada: siempre es María la que lo cuida, lo duerme, lo mima, etc 5 . Esta suerte de adopción simbólica del niño por parte de María parece establecer un pacto implícito con la madre biológica del niño: así como la madre adoptó a María, la joven judía toma a su cargo a Juan. Pero más allá de la conjetura de este pacto femenino de adopción, lo que la relación entre el niño y María nos sugiere es la imagen de cómo hubiera sido ella como madre, si hubiese podido casarse con Efraín, si hubiesen engendrado hijos, si no hubiese muerto antes.

Análogamente, los amores de los personajes secundarios - las bodas de Braulio y Tránsito y de Tiburcio y Salomé -, la familia feliz de José, el sueño final de Efraín en el capítulo XLIV (en el que aparece María vestida de novia) son otra indicación de lo que podría haber sido y no fue.

En los capítulos que preceden al viaje de Efraín a Londres, una vez que el protagonista ha intentado débilmente oponerse al deseo paterno de realizar estudios en Europa, el texto se focaliza en todos aquellos personajes y escenarios ajenos al núcleo familiar central. Paralelo a este cambio de foco narrativo, el tono pasa del romanticismo dramático, predominante tanto en los capítulos anteriores como en los posteriores, a un realismo costumbrista aligerado de tragedia, colorido y hasta etnográfico. ¿A qué se debe este progresivo énfasis en lo rural, en los personajes secundarios, en todo lo que rodea a la casa, justo

5 A este respecto, es ya clásica la escena del beso indirecto entre María y Efraín a través del niño. 
cuando la novela está por terminar? Argumentalmente, cumple la función de generar suspenso, pues retarda el desenlace de la historia central: el reencuentro de Efraín con María. Temáticamente, busca quizás enfatizar lo trágico de la muerte de la joven amada, pues las vidas de estos personajes rurales son irremediablemente felices y livianas. Sin embargo, creemos que su función central radica en el plano narrativo: esta veta casi etnográfica de los capítulos finales de María sostiene una crítica solapada pero firme a las reglas paternas, las verdaderas responsables de la tragedia. Lo que Efraín en tanto personaje nunca llega a decirle a su padre, la rebeldía que no logra manifestar en el plano de la ficción, sí logra expresarla Efraín narrador, a través del poder de la escritura, por ser él quien controla la narración. Al desplazar el acento del relato de lo paterno a lo circundante, de lo endogámico a lo exogámico, al suplantar progresivamente el interés narrativo en la casa paterna por el interés en los personajes ajenos a dicha casa (en sus viviendas y vestimentas, en sus relaciones, en sus diálogos, etc.), el texto ofrece a través de la organización de la escritura la rebeldía y el rechazo hacia lo paterno que el personaje, en el plano del contenido, no ha podido ni podrá expresar en ningún momento. De haber sido expresada por Efraín en tanto personaje, esta rebeldía podría haber evitado, tal vez, el viaje a Europa y la muerte de María.

Hay, pues, en María una constante ambivalencia. Por un lado, se narra un clima de malestar recurrente. Por otro, lo que Efraín y María dicen y hacen está siempre en armonía con su entorno humano (ambos jóvenes son enteramente bondadosos: nunca piensan mal de nadie, nunca proceden incorrectamente, nunca discuten ni pelean entre sí, son comprensivos, piadosos y gentiles en dosis ya inverosímiles). Esta bondad casi crispante, esta concepción de los personajes como seres monolíticos, sin ambages ni reveses, seres casi sin inconsciente (en este sentido, María es claramente una novela pre-freudiana) hace que el malestar, siempre presente, se desplace desde los personajes hacia las 
fuerzas superiores y externas: la naturaleza pasa a ser, entonces, la mejor condensación de este malestar.

El yo, voz y persona siempre privilegiados desde la estética romántica, tiene una especial conexión con la naturaleza o, mejor dicho, en María, texto romántico por excelencia, existe una comunión innegable entre los destinos de los seres humanos y ésta. Y dentro de esta comunión, los códigos no son difíciles de decodificar. Quizás el símbolo más evidente sea el ave de mal agüero cada vez que se acerca una desgracia en el orden humano. El poder, ya sea del pater familias o de la esfera celestial, tiene sus embajadores: así como la madre de Efraín es la mediadora entre el despótico padre y Efraín, de la misma forma el ave agorera "que se presenta cada vez que se anuncia una desgracia" (Jitrik, 2006, I8), nos anticipa veredictos (¿de dios, del destino o del padre?)

Pero la presencia romántica de una naturaleza exuberante y cuyas transformaciones están siempre en sintonía con los avatares humanos - alegorizan, anticipan, se hacen eco del destino de los personajes - no es sólo una cuestión de estilo romántico. La proliferación de descripciones que dan cuenta de una transferencia o reflejo del malestar humano en cuestiones climatológicas y paisajísticas tiene que ver, creemos, con la imposibilidad de pensar el conflicto por dentro de la esfera humana ${ }^{6}$. Sin embargo, a pesar del voluntarismo dialogal de presentar personajes transparentes, la figura del padre queda siempre salpicada de ambivalencia. Quizás por eso sea éste el personaje más interesante de la novela, o al menos el más parecido a personajes literarios del siglo veinte. La tensión entre lo que el texto nos refiere que hace el padre y lo que los personajes expresamente comentan de esa conducta paterna atraviesa

6 No sólo el malestar se hace eco en la naturaleza, también la felicidad se refracta, literalmente. Al respecto, Borello (1997) apunta que en las vidas de los primitivamente felices, básicos y terrenales personajes secundarios siempre hay sol y hace calor. 
toda la novela y sostiene en gran medida el interés del texto. Lo fascinante no es que este padre terrible y despótico sea una figura antagónica a los amantes, sino el juego constante de revelación y ocultamiento que sobre este personaje ejerce la novela: si en el plano narrativo el texto nos deja leer lo siniestro de la voluntad paterna, en lo dialogal no hay ningún registro de este autoritarismo. Los personajes - sobre todo Efraín y María - parecen ver sólo el lado bueno de este padre tan complejo ${ }^{7}$.

Las tres figuras principales de la novela son Efraín, María, en su lucha por la unión amorosa y, oponiéndose a este deseo, el padre. Mientras que la hermana, Emma, está del lado de los amantes, la madre apoya al padre. La primera escena es clave para entender la novela y, sobre todo, la lucha generacional, esa relación entre padre e hijo no demasiado divergente de aquella entre amo y esclavo. Luego de que una de sus hermanas le ha cortado un mechón de pelo, luego de haberse dormido llorando y de sentir un presentimiento de futuras penurias, el narrador cuenta:

A la mañana siguiente mi padre desató de mi cabeza, humedecida por tantas lágrimas, los brazos de mi madre. Mis hermanas al decirme sus adioses las enjugaron con besos. María esperó humildemente su turno, y balbuceando su despedida, juntó su mejilla sonrosada a la mía, helada por la primera sensación de dolor (53).

7 Los datos referentes al sistema de esclavitud y al poder del padre en tanto terrateniente (aunque en decadencia), proyectan esta misma falsa armonía a nivel social: ningún esclavo se rebela, ningún sirviente parece desconforme ante su situación pre-contractual, ningún campesino se queja de la diferencia social. Pero la idealización de este mundo jerarquizado no se sostiene tan fácilmente a nivel narrativo, pues la forma en que está narrada la novela, la escritura misma, nos sugiere en reiteradas ocasiones que la verdadera historia que está siendo narrada es la historia regida por la figura paterna y sus despotismos. 
La primera imagen que se nos trasmite del padre es como figura antagónica: no es casual que sea él quien "desata el nudo" que une al hijo con su madre. En reemplazo de este nudo, otra alianza parece establecerse ante la mirada vigilante del padre: las mejillas de Efraín y María, mediadas por el frío del dolor, simbolizan no sólo la historia amorosa que vivirán en el futuro los jóvenes sino, ante todo, su final trágico: nótese que en vez del esperable "calor" - o, al menos, "tibieza” - propio de lo amoroso y erótico, aquí se nos habla desde un principio del "frío del dolor". Esta segunda unión, sabemos, también será interceptada por el padre déspota.

Son varios los pasajes que dan cuenta de esta tensión entre lo que Efraín dice de su padre y lo que deja dicho el propio texto. En el capítulo V, donde se narra el paseo de ambos personajes por la hacienda, puede leerse esta ambivalencia. "Habían pasado tres días", se nos dice al inicio, “cuando me convidó mi padre a visitar sus haciendas del valle, y fue preciso complacerlo; por otra parte, yo tenía interés real a favor de sus empresas" (60). La expresión "fue preciso complacerlo" nos anticipa la obediencia que rectifican el nexo "por otra parte" y el adjetivo "real”: dos fuerzas en pugna conviven en Efraín. Por un lado, la falta de ganas por hacer esa excursión y, por el otro, el interés en las empresas paternas que - ¿por qué hace falta aclararlo? - es real. La tensión entre la bondad del padre que Efraín explicita y la imagen autoritaria que de él nos brinda el narrador se percibe también hacia el final del capítulo:

Quedó mi padre satisfecho de mi atención durante la visita que hicimos a las haciendas; mas cuando le dije que en adelante deseaba participar de sus fatigas quedándome a su lado, me manifestó, casi con pesar, que se veía en el caso de sacrificar a favor mío su bienestar, cumpliéndome la promesa que me tenía hecha de tiempo atrás, de enviarme a Europa a concluir mis estudios de medicina, y que debía emprender viaje, a más tardar dentro de cuatro meses. (59) 
¿Es porque “deseaba participar de sus fatigas" que Efraín quiere quedarse en la hacienda? Obviamente, no. La verdadera razón, lo sabemos, es María. La buena conducta del joven a lo largo de ese paseo emprendido sin demasiado entusiasmo ("Quedó mi padre satisfecho de mi atención durante la visita”) y esta mentira (“deseaba participar de sus fatigas") van anticipando el miedo del joven hacia su padre. La negativa paterna ante el pedido de Efraín de quedarse con la familia reviste no poco cinismo: el padre dice que lo enviará a Europa sacrificando el propio bienestar a favor de Efraín, en cumplimiento de una promesa hecha hace años. El malestar se sostiene porque los lectores sabemos - nos lo dice el texto constantemente - que Efraín no ha pedido ir a Europa ni exige que se cumpla ninguna promesa al respecto. El viaje es exclusivamente beneficio del padre, o cuanto mucho del grupo familiar, pero no de Efraín. El despotismo del padre se intuye de nuevo: “Al hablarme así, su fisonomía se revistió de una seriedad solemne sin afectación, que se notaba en él cuando tomaba resoluciones irrevocables" (63). El dolor que presagiaba Efraín en la primera escena de la novela (al despedirse, siendo sólo un niño, de su hogar para cursar los primeros estudios) se corrobora con la noticia de una segunda separación infligida de nuevo por el padre. Lejos de narrar cómo hizo frente a este autoritarismo, Efraín narra su sometimiento melancólico:

Esto pasaba la tarde en que regresábamos a la sierra. Empezaba a anochecer y, a no haber sido así, habría notado la emoción que su negativa me causaba. El resto del camino se hizo en silencio. (¡Cuán feliz hubiera yo vuelto a ver a María, si la noticia de ese viaje no se hubiese interpuesto desde aquel momento entre mis esperanzas y ella!) (63).

Complementario al lamento por todo lo que podría haber sido y no fue, las órdenes del padre parece aceptarse con la misma pasividad con que se aceptan los fenómenos naturales o las decisiones atribuidas a un dios. Junto con la lectura del fracaso del amor a raíz de causas inmanejables (la enfermedad de 
María como una herencia de su madre), el texto desliza constantemente pistas que permiten atribuir el fracaso de la unión amorosa al padre. Es el padre, por ejemplo, quien informa acerca de la enfermedad de María, información que luego es corregida por la madre de Efraín. En el capítulo XIV María ha sufrido un ataque de nervios y está en coma. Allí aparece la primera versión paterna acerca de la salud de la joven judía y reaparece una vez más el padre en su función de vigía entre los jóvenes enamorados: "Olvidado de toda precaución, entré a la alcoba donde estaba María [...] me acerqué desconcertado a su lecho. A los pies de éste se hallaba sentado mi padre: fijó en mí una de sus miradas intensas, y volviéndola después sobre María, parecía quererme hacer una reconvención al mostrármela (80)". Es obvio que la actitud del padre es una condena a la unión de Efraín y María. Es de boca del padre, no casualmente, de donde sale el diagnóstico fatal: “- Todo ha pasado. ¡Pobre niña! Es exactamente el mismo mal que padeció su madre" (80). El hecho de que sea el padre el transmisor de este supuesto saber médico se rescata una vez más en el capítulo siguiente: "Recostado en una de las columnas del corredor, sin sentir la lluvia que me azotaba las sienes, pensaba en la enfermedad de María, sobre la cual había pronunciado mi padre tan terribles palabras" (8I). A lo largo de estos ataques de María (narrados entre los capítulos XIV, XV, XVI y XVII), el médico no tiene voz propia: sus diagnósticos y recomendaciones nos son referidas siempre por otro personaje (el padre o la madre), pero nunca escuchamos directamente la palabra de Mayn. De hecho, entre el final del capítulo XV - "me desmonté a la puerta de la casa donde vivía el médico" (84) - y el inicio del capítulo XVI -“En la tarde del mismo día se despidió de nosotros el doctor” (84) - hay una elipsis importante: no se cuenta cómo fue el viaje del médico a la casa, ni en qué consistió su visita, ni qué diagnóstico y pronóstico hizo sobre la enferma ${ }^{8}$.

8 Tanta es la incertidumbre que esta elipsis deja librada, que hasta podría ser blanco de una parodia al estilo de la que hizo Moreno Durán en "El capítulo inglés” (El humor de la melancolía, 2000). 


\section{EL PRESTIGIO SOCIO-CULTURAL DEL DOLOR}

Efraín ha confiado en el amigo del mismo modo que nosotros, lectores, confiamos en la veracidad del dolor que es narrado. Éste es el pacto de lectura para las novelas sentimentales en el siglo XIX (Molloy, I984, 37). Algo queda claro: tanto para los personajes dentro de la novela como para la obra en tanto objeto estético, las lágrimas y el dolor ennoblecen. Lo trágico tiene más positividad moral que lo cómico, así como el amor irrealizado tiene más prestigio social que los amores carnalmente satisfechos. A tono con la moralina católica, para los románticos del diecinueve, la abstinencia ennoblece y el amor imposible embellece:

Para Isaacs el amor imposible sólo podía tener lugar en el más elevado nivel social. Y, dentro de ese nivel, debía estar quien alcanzaba hasta lo más alto: la infelicidad y la muerte [...] porque expresaba toda una axiología que suponía que la más deseable forma de existencia era la del amor no realizado (Borello, I997, 78).

José Promis también propone que la cuestión del dolor tiene que ver con el prestigio social, en una cadena semántica que une: elevación socio-económica, sofisticación del espíritu, capital simbólico (ser letrado), amor imposible, dolor. La distancia entre el sentir de Efraín y el del propio Isaacs no es grande: al hablar del proceso de escritura de su novela, el autor se posiciona en un lugar de privilegio social a través del dolor: “¡Páginas queridas, demasiado queridas quizás! Mis ojos han vuelto a llorar sobre ellas. Las altas horas de la noche me han sorprendido varias veces con la frente apoyada sobre estas últimas, desalentado, para trazar algunos renglones más” (citado por Cantavella, I996, 97). Esta concepción del dolor y del amor imposible como valores socialmente prestigiosos - junto con otros rasgos textuales que han sido leídos como recomendables para educar a los jóvenes colombianos -, son los rasgos textuales de María que han marcado las primeras lecturas críticas y, quizás, han “escolarizado” el texto. 
O tal vez deberíamos preguntarnos, ¿qué de María se consideró ejemplarizante?, si aceptamos que el criterio del siglo XIX para incluir una novela en la currícula era: se enseñan aquellos textos en que los lectores puedan tranquilamente - tranquilidad: es decir, ausencia de transgresión o cuestionamiento de la cultura vigente - identificarse con los protagonistas, "copiar" las conductas y actitudes de los personajes. Esto es: la literatura se concibe como importante transmisor ideológico y la audiencia, con cierto bovarismo: contagiable fácilmente por aquello que lee. De ahí que las novelas elegidas deban ser moralmente altas. Y así se leyó María desde el mismo año de su publicación. Para José María Vergara y Vergara, autor de la Historia de la Literatura de la Nueva Granada (I867), figura clave en el proceso de construcción del patrimonio cultural:

María es la narración de los amores de dos jóvenes, rodeados de muchas personas, viviendo en una misma casa y profundamente enamorados. Por lo tanto, la pintura de su amor es más fecunda, más interesante, pero más delicada por más peligrosa. Y sin embargo, es tan casta, que así como los dos amantes no se dijeron una sola palabra que no pudieran oír sus padres, así en el libro no hay una página que no pueda leer una madre de familia (Citado por Promis, I991, 67).

Faltarán muchos años y mucha tinta para que la crítica pueda distanciarse de la mirada que hace primar la historia de amor por sobre otros elementos literarios de María. Como podemos ver en esta cita, lo que más atrae a Vergara en tanto agente cultural que selecciona qué se lee y cómo se lo lee, es el tema de la castidad, la contención de los jóvenes que no se dejan arrebatar por sus impulsos sexuales. La represión supone, no ya falta de deseo, sino la primacía de lo correcto, familiar, socialmente pautado por sobre la búsqueda de satisfacción personal. Es lo sacrificial de este amor - tinte católico, abstenido, dictado por el deber ser social - lo que torna a esta historia ideal para ser enseñada, jincluso ante las madres de familia! (¿Acaso parangones de la moral, preocupadas sólo 
por educar a su prole o acaso las lectoras más tentables y a quienes, por ello, es necesario mantener lejos de cualquier relato sexual?)`9. La cuestión del público femenino recurre: no sólo la novela parece dedicada a las mujeres - tal vez por el énfasis textual en las lágrimas, por su sentimentalismo, tal vez - sino que las mujeres, por ser según Vergara intrínsecamente puras y castas, difunden la buena semilla literaria, ennoblecen el texto con sus ojos lectores:

María hará largos viajes por el mundo, no en las valijas del correo sino en las manos de las mujeres, que son las que popularizan los libros bellos. Las mujeres la han recibido con emoción profunda, han llorado sobre sus páginas y el llanto de las mujeres es verdaderamente el laurel de la gloria (Citado por Promis, I99I, 68).

La idea de María como una historia de amor platónico, no consumado (la crítica del XIX insiste en la castidad como en una victoria), que derrama virtud e inocencia, cuyos personajes carecen de maldad y son transparentes, ha persistido por varias décadas y culturas. El poeta mexicano Manuel Gutiérrez Nájera, por su parte, la lee como "un libro casto, un libro sano, un libro honrado" (Promis, I99I, 69). Recién en los años setenta, y luego de la iluminadora lectura de Anderson Imbert en los cincuenta (quien empezó a plantear la cuestión social complicada en María... el atisbo de la hilacha vergonzante que luego verá Ordóñez como primando por sobre otros elementos), llegaremos a un reconocimiento de la conflictividad en la novela. A partir de la sociología de la literatura, se la pudo empezar a leer como un testimonio de la desintegración de la aristocracia agraria colombiana, como una expresión de la naturalización

9 Cabría todo un análisis feminista - o una parodia al estilo de la de "El capítulo inglés" - en torno a los supuestos de género que quedan implícitos en la frase "no hay una página que no pueda leer una madre de familia", pero aquí bástenos decir que se hace evidente la prescripción moralizante que le otorga la crítica del XIX a María. 
POR QUÉ SIGUE LLORANDO EFRAíN O CÓMO LEEMOS MARÍA EN EL SIGLO XXI

NATALIA CRESPO

del sistema de esclavitud por parte de la clase terrateniente, como alegato de una sociedad patriarcal que delimita los espacios según los géneros (masculino-vida pública vs. femenino- privado).

En lo que va del siglo XXI, la novela se ha leído varias veces haciendo hincapié en cuestiones de diversidad cultural, a tono con el interés de nuestra época neoliberal en el multiculturalismo. Así, han aparecido lecturas como las de Eva-Lynn Jagoe, Faverón Patriau y Noé Jitrik, que indagan en torno al judaísmo de Isaacs - en parte retomando ideas planteadas por Doris Sommer en su clásico análisis de la novela - y textos como los de Lucía Ortiz, Patricia D’Allemand o David Musslewhite, en donde se tematiza la exclusión de los negros.

Esta masa crítica estaría de acuerdo, especulamos, con la aseveración de Ordóñez de que la literatura del siglo XIX presenta una cara de nosotros mismos con la que no queremos identificarnos, versiones vergonzantes de lo que fuimos. De la marmolización a la vergüenza, sin embargo, María se sigue leyendo y, sobre todo, se sigue re-escribiendo paródicamente: quizás “El capítulo inglés", de R. H. Moreno Durán, sea la mejor respuesta que podemos dar, no tanto a lo que la novela muestra del siglo XIX sino, más concretamente, a lo que se le atribuía desde quienes museificaban la literatura: los constructores del canon, al estilo de Vergara y Vergara. 
Beane, Carol A, "Los contornos discursivos del África de María". La historia en la literatura iberoamericana. Memorias del XXVI Congreso del Instituto Internacional de Literatura Iberoamericana. Ed. Raquel Rodríguez Chang y Gabriela de Beer. New York: Ediciones del Norte, University of New York, I987.

Borello, Rodolfo, "Sociedad y paternalismo en María". Cuadernos Hispanoamericanos 562, (I997): 67-79.

Cantavella, Juan, “Miradas y lágrimas en María, de Jorge Isaacs”. Cuadernos Hispanoamericanos 552, (1996): 93-99.

D'Allemand, Patricia, "Of Silences and Exclusions: Nation and Culture in Nineteenth-Century Colombia”. Contemporary Latin American Cultural Studies. Ed. Stephen Hart and Richard Young. London: Arnold, 2003.

Díaz Balsera, Vivian, “María y los malestares del paraíso”. Hispanófila I23.4I (I998): 37-53.

Faverón Patriau, Gustavo, "Judaísmo y desarraigo en María de Jorge Isaacs", Revista Iberoamericana 70.207 (2004): 34I-57.

Isaacs, Jorge, María. Ed. Mc Grady. España: Gredos, I984.

Jagoe, Eva-Lynn Alicia, “Las herencias colombianas: corporrealidad y colonización en la obra de Jorge Isaacs”. Cuadernos Americanos I7. 6.102 (2003): I44-62.

Jitrik, Noé, “El secreto encanto de Jorge Isaacs”. Poligramas 25 (2006): II-22.

Lagos-Pope, "Estructura dual y sociedad patriarcal en María". Revista de Estudios Colombianos 8 (I990): I2-20.

Molloy, Silvia, "Paraíso perdido y economía terrenal en María”. Sin nombre I4.3 (I984): $36-55$. 
POR QUÉ SIGUE LLORANDO EFRAíN O CÓMO LEEMOS MARÍA EN EL SIGLO XXI

NATALIA CRESPO

Musselwhite, David, “The Colombia of María. Un país de cafres”. Romance Studies 24.I (2006): 4I-54.

Ordóñez, Montserrat, Una nueva lectura de la obra de Soledad Acosta de Samper. Bogotá Fondo de Cultura Cafetero. 401 p.I988.

Ortiz, Lucía, “El negro y la creación romántica de una identidad nacional. Hacia una relectura de María de Jorge Isaacs”, Ed. Lucía Ortiz. Madrid, Spain; Frankfurt, Germany: 2007.

Promis, Jorge, "Las tres caras de María. (Lectura de las lecturas de la novela de Jorge Isaacs". Signos 24.29 (I99I): 67-75.

Sommer, Doris,"El mal de María: (Con)fusión en un romance nacional”. MLN I04.2 (I989): 439-474.

Zanetti, Susana, “María de J. Isaacs y los problemas de constitución de un canon de América Latina. Aspectos internacionales de independencia literaria”. Ed. Bárbara Buchenau, Annette Paatz. Do the Americas Have a Common literary History? Göttingen: Wallstein, 200 I. 
